\title{
Comunicación

\section{De la concentración a la convergencia. Políticas de medios en Argentina y América Latina}

CECILIA BEATRIZ DÍAZ1

El inicio del siglo XXI en Latinoamérica estuvo signado por los debates, leyes regulatorias y nuevas políticas de comunicación que marcaron una ruptura respecto del modelo neoliberal implementado en la década de los noventa. Sin embargo, ese proceso no fue homogéneo en la región, ya que presenta matices y discusiones que enfrentan a los principales actores de la comunicación. En ese contexto, el doctor en Ciencias de la Comunicación Martín Becerra, publicó De la Concentración a la Convergencia. Políticas de Medios en Argentina y América Laque opacó los intentos por pensar los alcances de los modos de intervención de los Estados en la construcción de lo público en el espacio mediático.

1 Consejo Nacional de Investigaciones Científicas y Técnicas (Conicet) y Universidad Nacional de La Plata, Argentina.

Correo electrónico: diaz.ceciliab@gmail.com 
La vasta trayectoria de Martín Becerra en la investigación de la economía política de la comunicación lo posicionó como referente del tema sobre la regulación de la concentración de los grupos mediáticos. Es investigador del Consejo Nacional de Investigaciones Científicas y Técnicas (Conicet), especializado en políticas de la comunicación, la cultura y la tecnología, así como docente de grado y postgrado en comunicación social en universidades públicas; ha editado sus análisis sobre los escenarios tanto nacionales como regionales en revistas especializadas, congresos internacionales, libros y diarios donde suele ser consultado por su conocimiento del campo.

Desde la contratapa se anuncia un análisis acerca de las políticas públicas de medios "exhaustivo, documentado y sin fanatismos", expresión que cobra sentido en el escenario argentino que tiene como punto de quiebre el anuncio del proyecto de la Ley de Servicios de Comunicación Audiovisual (LSCA) en 2009, durante el gobierno de Cristina Fernández de Kirchner, a partir del cual se desató una discusión pública polarizada en los medios, en el debate político y que alcanzó a la academia. En este libro se evidencia el esfuerzo por superar posturas binarias al hacer concesiones a ambos discursos, aunque en las fuentes citadas se relativiza el intento del equilibrio.

Becerra sostiene a lo largo de este recorrido que el sistema argentino de medios es protocapitalista, es decir, que a pesar de la histórica concentración, la industria requiere del financiamiento del Estado, ya sea en la inversión de infraestructura, en el reparto preferencial de la publicidad oficial, de exenciones impositivas o sectores desregulados para conformar posiciones dominantes.

Tal como lo sugiere el título, la obra construye un hilo conductor entre el proceso de concentración de los medios tradicionales (gráfica, radio y televisión) hasta la problemática de la regulación sobre la convergencia. En ese trayecto no solo hay cambios tecnológicos, sino transformaciones profundas en el modo de acceder a la información y entretenimiento, que problematizan los parámetros para pensar políticas públicas en sintonía con la democracia.

La obra se compone de seis capítulos. En el primero, se lleva a cabo un recuento histórico de las últimas tres décadas de políticas públicas de comunicación en Argentina; es decir, del periodo democrático en el 
que la principal forma de daño al ejercicio de la libertad de expresión ya no es la censura sino el proceso de concentración en el sector, situación que Becerra junto con otros investigadores han abordado en Los Dueños de la Palabra: Acceso, Estructura y Concentración de los Medios en la América Latina del Siglo XXI (2009) y Estructura, Concentración y Transformaciones en los Medios del Cono Sur Latinoamericano (2011), obras que configuran, que configuran un estado de la cuestión del escenario de las industrias infocomunicacionales.

Así mismo, en ese primer capítulo se examina el debate, sanción y aplicación de la LSCA (2009) en la política de medios del kirchnerismo (2003-2007, 2007-2011, 2011-2015) y en lo que el propio oficialismo ha dado a llamar "la batalla cultural". La elección de este hito no es arbitrario, dado que implicó la regulación bajo el paradigma de la comunicación como bien social (Díaz, 2013) y que fomentó la participación y el debate más allá de los circulos académicos.

El autor distingue el proceso de la LSCA con claroscuros, responsabilidades compartidas y tensiones que complejizan la lectura de este momento en la historia argentina de regulación de medios de comunicación. Por una parte, Becerra destaca los avances de la legislación en cuanto que reconoce al tercer sector, sin fines de lucro, de la comunicación, garantizándole un porcentaje del espectro radioeléctrico igual al destinado a medios privados y públicos. De este modo, se establece una base para el pluralismo informativo y cultural, requisito para enriquecer el debate democrático. Logros que no surgen solo de la iniciativa del oficialismo, sino que son la traducción de la lucha de múltiples organizaciones y colectivos sociales, desde los inicios del presente periodo iniciado en 1983.

Sin embargo, Becerra señala las tramas partidarias que potenciaron y limitaron, a su vez, el debate de la regulación; principalmente, la pugna entre el conglomerado de medios Clarín y el gobierno de Cristina Fernández de Kirchner que dio lugar al impulso de la mayoría parlamentaria para la sanción de la LSCA. Por otro lado, reconoce que el proyecto original que llegó al Congreso era más ambicioso al incluir en la regulación a los servicios convergentes y ponía en discusión el lugar de las telefónicas (que en Argentina tienen vedada la participación en medios audiovisuales por otra legislación anterior que las circunscribe 
a brindar un único servicio público). Pero este apartado fue descartado por un sector de la oposición que cuestionaba el acceso a mejores condiciones a las empresas de telecomunicaciones que podría llevar a nuevos abusos de posición dominante. Si bien esta línea de partidos minoritarios estaban a favor del texto legal en general, su negación obturó la posibilidad de debatir la convergencia y obtener una legislación más actualizada y más detallada respecto de conceptos como la neutralidad de la red, sostiene el autor.

De la misma forma, Becerra explica que la aplicación de la ley por parte del poder ejecutivo también estuvo signada por afinidades y tiempos políticos, y no por la necesidad de los actores en conflicto, mientras que los grupos de multimedios litigaban los alcances de la LSCA con base en derechos de propiedad y libertad de expresión, estrategia que el autor define como dilatoria, para aguardar al cambio de signo político en el gobierno, ya que el fallo de la Corte Suprema de Justicia por la constitucionalidad de la ley era previsible. En esa pugna, los actores que fueron perjudicados son el tercer sector (cuya situación no se tradujo en presencia en el espectro radioeléctrico) y las audiencias, quienes no reciben una oferta plural y diversificada de servicios e información.

En el segundo capítulo se retoma la concentración de medios no solo como un concepto abstracto sino operacionalizado y problematizado en cuanto a su medición. Así mismo, fundamenta ese indicador como una condición del ejercicio pleno de la libertad de expresión según el Sistema Interamericano de Derechos Humanos, al que Argentina se adhiere.

En esta línea, Becerra releva las metodologías para dar cuenta de la concentración, lo cual es un aporte de edición a los investigadores, al tiempo que explica la dificultad de llevar a cabo ese tipo de mediciones, dado que no hay accesibilidad a información de carácter público ni privado en América Latina. Al respecto, explica que la falta de datos que permiten describir el estado del sector infocomunicacional repercute en el diseño de políticas públicas.

Otra situación particular de este proceso de mayor intervención de los Estados en la comunicación es el surgimiento de nuevas señales de televisión pública, que Becerra analiza en el tercer capítulo. También hay clarososcuros, dado que el sentido de lo público es reemplazado 
por lo gubernamental, afirma el autor. Aquí el problema es: ¿qué es lo público?, ¿cuáles son los paramétros de lo público en los medios de comunicación? Dado que las características de la región son muy lejanas a los estándares de la Organización de las Naciones Unidas para la Educación, la Ciencia y la Cultura (Unesco), Becerra se vale de la definición de Rincón (2014): los medios públicos son todo aquello que los comerciales no son. Sin embargo, reconoce un aumento en la calidad y la diversidad en los canales culturales que se disipa en los géneros periodísticos. Este análisis lo sostiene citando al estudio sobre pluralismo de fuentes de la Defensoría del Público, ente creado por la LSCA. En suma, el comunicólogo sentencia que en América Latina, la tarea pendiente es la construcción del espacio de lo público y de ese modo cierra su contrapunto con Rincón.

Esta discusión no cerrada por el interés público afecta a otra categoría que es la publicidad oficial. En efecto, es obligación del Estado hacer públicos los actos de gobierno, pero en el último tiempo este mandato fue objeto de disputas en el contexto argentino. Al respecto, Becerra realiza un análisis en el cuarto capítulo, al considerarla como una política de medios que en general es poco explorada en los estudios académicos, dado que es una práctica no institucionalizada que revela la relación entre los gobiernos y la política.

En el quinto capítulo se contextualiza la particularidad del proceso de regulación en América Latina respecto del resto del mundo y la califica como "a contramano". Esto se lo atribuye debido al enfrentamiento entre poder político y mediático, al tiempo que los medios experimentan una transformación de su ecosistema: la convergencia. En ese apartado, Becerra concluye que las regulaciones suponen más desafíos en pos de articular los sentidos democráticos y republicanos asociados a la comunicación.

En este escenario, el autor construye un panorama de los debates inconclusos acerca de la regulación de la convergencia que no solo son la representación de América Latina sino también de Europa. Por ejemplo, las múltiples infraestructuras de Internet y su extensión transfronteriza, eluden los clásicos límites de los Estados nación y de la propiedad. De ese modo, el capítulo seis trata la cuestión postindustrial de la comunicación, es decir, la lucha no es sobre la propiedad sino sobre el acceso 
a los bienes culturales. En esa línea se relevan avances y desafíos en las legislaciones más actuales del mundo occidental.

En conclusión, De la Concentración a la Convergencia. Políticas de Medios en Argentina y América Latina propone una lectura en una primera etapa de un proceso vertiginoso y cargado de complejidad que lejos de cesar, produce nuevos desafíos que problematizan las categorías más clásicas sobre lo público, lo social y lo comercializable. En ese sentido, la obra de Becerra adquiere relevancia y constituye un aporte al estado de la cuestión sobre regulación de medios.

\section{Bibliografía}

Becerra, M. \& Mastrini, G. (2009). Los dueños de la palabra: acceso, estructura y concentración de los medios en la América Latina del Siglo XXI. Buenos Aires, Argentina: Prometeo.

Becerra, M. \& Mastrini, G. (2011). Estructura, concentración y transformaciones en los medios del Cono Sur latinoamericano. Comunicar, 36 (XVIII), 51-55.

Díaz, C. B. (2013). Encuentro: inicio hacia una comunicación democrática. Trampas de la Comunicación y la Cultura, 75, 39-44.

Rincón, O. (6 de noviembre de 2014). La ilusión de los medios públicos en América Latina. Conservatorio regional Construyendo una democracia efectiva: el papel de los medios de comunicación. Bogotá, Colombia. 